\title{
Extension of the Process Window in Laser Chemical Machining by Temperature-Dependent Reduction of the Electrolyte Viscosity
}

\author{
Marcel Simons ${ }^{1} \cdot$ Tim Radel $^{1} \cdot$ Frank Vollertsen ${ }^{1,2}$
}

Received: 4 November 2020 / Revised: 14 April 2021 / Accepted: 25 May 2021 / Published online: 28 June 2021

(c) The Author(s) 2021

\begin{abstract}
The laser chemical process is a material-removing machining process in the micro range. The process is based on a laserassisted etching process between an electrolyte and a metallic workpiece. Local overheating causes a laser-induced electrolyte boiling process, which limits the laser chemical process window. In order to reduce the laser-induced electrolyte boiling process and thus expand the process window, the laser chemical process is carried out at different electrolyte start temperatures and thus different electrolyte viscosities and surface tensions. The experimental investigations were carried out on Titanium Grade 1 with the electrolytes phosphoric acid and sulfuric acid at different electrolyte temperatures and laser powers to determine the limits of the process window by evaluating the properties of the removal cavities. As a result, the process window is extended at lower electrolyte viscosities. Thereby, the electrolyte viscosities have no influence on the geometric shape of the removal. The extension of the process window is attributed to the fact that a reduction in electrolyte viscosity results in a less pronounced formation of the boiling process, the bubble diameters decrease, and the shielding effect of the bubbles is reduced.
\end{abstract}

Keywords Laser micro machining $\cdot$ Laser chemical removal $\cdot$ Viscosity $\cdot$ Removal rate $\cdot$ Quality

\section{Introduction}

As the demand for miniaturized components continuous to grow, so do the requirements for production technology. Conventional machining processes such as turning, milling or grinding are increasingly reaching their technical limits. Among other mechanisms, high tool wear and high thermal and mechanical component loads, which can lead to changes in the material properties on the surface or to deformation of the component, must be mentioned in particular [1]. In order to meet the increasing demands on complexity and multifunctionality of the components to be produced, so-called non-conventional machining processes have been developed [2]. These include laser material processing (LBM) due to the precise, local and flexible application of energy and electrochemical machining (ECM) due to the gently removal of

Marcel Simons

simons@bias.de

1 BIAS - Bremer Institut für angewandte Strahltechnik, Klagenfurter Straße 5, 28359 Bremen, Germany

2 University of Bremen, Bremen, Germany material [3]. The advantages of the above-mentioned processes are combined in laser chemical machining (LCM).

Laser chemical machining represents a material removing surface treatment through the effect of laser-induced thermal activation of heterogenous chemical reactions between an electrolyte and a metallic surface [4]. The selective surface modification is possible for all metals that form a passivation layer at room temperature and thus protect the workpiece from corrosion in the electrolyte bath. Due to the low laser power density compared to other laser material machining methods, changes in the properties of the microstructure and melt formation are avoided [5]. Since laser chemical machining is a mainly temperature-dependent process, the process window is significantly limited by local, laser-induced electrolyte boiling and the resulting shielding effect of the gas bubbles depending on the gas bubble diameter and the adhesion time of the gas bubbles on the workpiece surface, which leads to a reduction in the quality of the removal cavities [6].

By enlarging the spot diameter for large workpiece surfaces by a factor of 10.8 , the machining time could be reduced by two orders of magnitude [7]. One way to reduce the electrolyte boiling process is to perform the laser chemical process at increased process pressures. When the process 
pressure was increased to 6 bar, a 27\% reduction in gas bubble diameters was registered [8].

Furthermore, the laser-induced electrolyte boiling process, which limits the laser chemical process window, can be minimized by a reduction of the electrolyte viscosity [9]. To reduce the electrolyte viscosity, the electrolyte start temperature was increased. In addition to the resulting reduction in viscosity, the surface tension is also reduced by increasing the electrolyte start temperature. A reduction in surface tension also leads to a drop in the electrolyte boiling process. This was determined both by experimental studies on alcohol-water mixtures [10] and by modeling the gas bubble diameters [9]. The reduction on viscosity is described as the dominant effect [10].

In the present work the effect of viscosity reduction was applied to extend the laser chemical process window. For this purpose, different removal experiments were performed with different process parameters, e.g. laser power and machining speeds at different electrolyte start temperatures. The gas bubble formation was recorded during the experiments using high-speed shadow videography and the removal cavities were examined by confocal microscopy after the experiments.

\section{Materials and Methods}

\subsection{Experimental Set-Up}

The beam source was an IPG cw-fiber-laser (YLR-100-AC) with a wavelength of $1070 \mathrm{~nm}$. The fiber core has a diameter of $10 \mu \mathrm{m}$. In the beam path, the radiation, which has a Gaussian intensity, was collimated with a collimator lens with a focal length of $36 \mathrm{~mm}$. The collimator lens was followed by a beam attenuator. This allowed the power control on $0.1 \mathrm{~W}$ steps. With the help of a lens system with a focal length of $93 \mathrm{~mm}$ a focus diameter of $25 \mu \mathrm{m}$ could be achieved on the workpiece, see Table 1.

The applied laser power in the workpiece was $0.6-3.0 \mathrm{~W}$. This ensured that all removal regimes of laser chemical machining were covered [6].

Titanium Grade 1 with the dimensions of $20 \mathrm{~mm} \times 20 \mathrm{~mm} \times 1 \mathrm{~mm}$ was used as workpiece material. Before clamping the specimens in the chemical cell, see

Table 1 List of experimental properties

\begin{tabular}{llll}
\hline & Parameter & Unit & Value \\
\hline Laser beam (continuous wave) & Wavelength & $\mathrm{nm}$ & 1070 \\
& Laser power & $\mathrm{W}$ & $0.6 \ldots 3.0$ \\
& Focus spot diameter & $\mu \mathrm{m}$ & 25 \\
& Machining speed & $\mu \mathrm{m} / \mathrm{s}$ & 50 \\
\hline
\end{tabular}

Fig. 1, the titanium workpieces were ground to guarantee a uniform surface roughness. Due to the correlation between surface roughness and the number of gas bubble nuclei, an even number of gas bubble nuclei can be guaranteed for all experiments.

A 5 molar phosphoric acid and a 1.9 molar sulfuric acid was passed through the chemical cell, compare Fig. 1. Due to the geometric shape of the chemical cell, the propagation length was $46 \mathrm{~mm}$. This resulted in a transmission coefficient of 0.44 . The laser chemical cavities were created at a machining speed of $50 \mu \mathrm{m} / \mathrm{s}$ and had a length of $0.5 \mathrm{~mm}$.

With the help of the RC6 temperature control system from "Lauda", the temperature of the electrolyte (electrolyte start temperature) was controlled during machining. Electrolyte start temperature is the temperature at which the electrolytes are transported into the chemical cell.

Among other specific properties, the surface tension and viscosity are changed by the varying electrolyte start temperatures (Fig. 2). The viscosity and the surface tension were determined according to DIN 53019-1 [11] and DIN EN 14370 [12], respectively.

In addition, the specimens were brought to a temperature of $20^{\circ} \mathrm{C}$ before machining. Furthermore, a cooling system was integrated into the chemical cell to ensure a constant specimen temperature. Moreover, the contact time of the specimens with the tempered electrolytes was reduced to a minimum. Due to these measures, the change of the specimen temperature caused by the electrolyte start temperature could be neglected. To understand the etching during the machining time due to increased electrolyte start temperatures, the background etch rate for Titanium Grade 1 was determined inspired by DIN 50905 [13] or all electrolyte start temperatures used. Due to a maximum background etch rate of $0.0000102 \mathrm{~mm} / \mathrm{s}$ when using sulfuric acid, background etching was neglected.

To evaluate the laser chemical cavities, they were recorded with a confocal microscope (50X objective). The images were processed with the VK-Analyzer Software. Of particular interest were the depth and width of the cavities. The evaluation of these parameters was done analogous to [6] with Matlab. The evaluated depths and widths

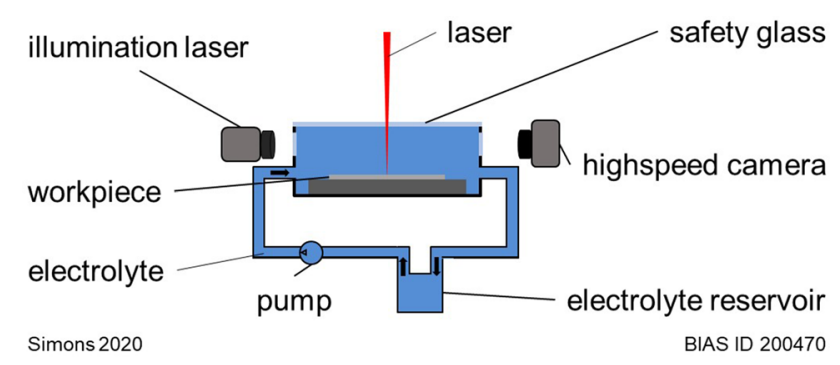

Fig. 1 Schematic representation of the experimental set-up 
Fig. 2 Representation of the temperature-dependent electrolyte viscosities and surface tensions

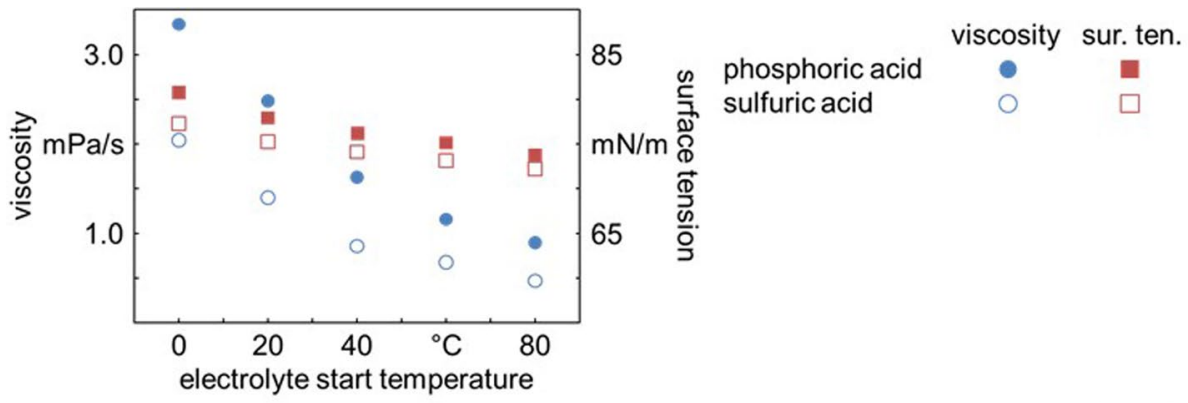

Simons 2020 of the removal allowed the calculation of the removal rate according to Eq. (1). Here the $l_{r}$ stands for the length of the removal, $v_{s}$ for the machining speed, $V_{r}$ for the removal volume and $v_{r}$ for the removal rate.

$v_{r}=\frac{V_{r}}{l_{r}} \times v_{s}$

Besides the evaluation of the removal rate of the laser chemical cavities, the laser chemical cavities were divided into three regimes according to their shape, based on the format of [14]. In Fig. 3 the removal regimes, no removal, undisturbed, gaussian-shaped removal a disturbed, w-shaped removal are shown exemplarily.

For the observation of the laser chemical interaction zone the transmitted light method with the help of a high-speed camera, see Fig. 1, was applied. The highspeed images were taken with $256 \times 256$ pixels and frame rates of 22,000 frames per second. One camera pixel corresponded to a square surface with a side length of $1.75 \mu \mathrm{m}$. A Matlab-based videographic analysis program was developed to evaluate the high-speed images generated [8]. First the high-speed recordings were segmented into individual frames, see Fig. 3. Subsequently, the area of the laser chemical interaction zone was determined. This area describes the point of laser action on the workpiece-electrolyte interface. By means of a pixel intensity adjustment, the edges of closed surfaces were detected within this interaction zone. The geometrically closed surfaces were assumed to be round, whereby their radius could be determined. The diameter of the gas bubbles was detected at the moment of tearing off from the workpiece surface. In addition, the percentage of time in relation to the total experimental time during which gas bubbles were in contact with the workpiece surface was determined.

\section{Results}

\subsection{Evaluation of the Removal Cavities}

Figure 4 shows the characteristics of laser chemical removal at different electrolyte start temperatures using phosphoric acid and sulfuric acid. The different electrolyte start temperatures have no influence on the regime of non-existent removal regardless of the electrolytes used. Considering the regime of the undisturbed removal, an extension of the process window can be seen when the electrolyte start temperature is increased from 0 to $80{ }^{\circ} \mathrm{C}$ both when using phosphoric acid and sulfuric acid. The transition from the
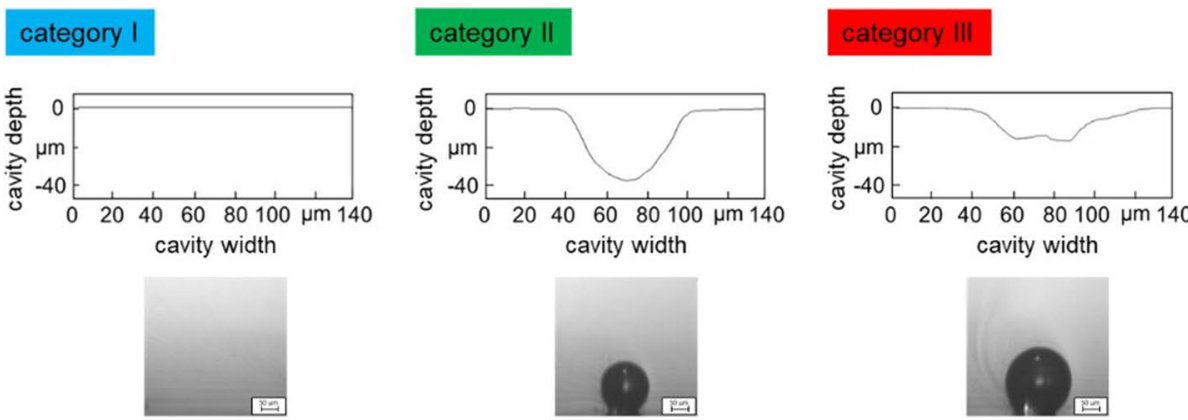

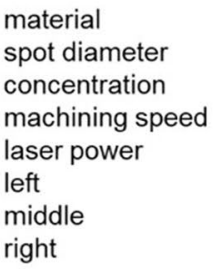

Titanium Grade 1

$25 \mu \mathrm{m}$

$5 \mathrm{~mol} / \mathrm{L}$

$50 \mu \mathrm{m} / \mathrm{s}$

$0.6 \mathrm{~W}$

$1.0 \mathrm{~W}$

$1.8 \mathrm{~W}$

Fig. 3 Classification of the removal regimes during laser chemical machining inspired by [6] (cavity profile and highspeed frames) 


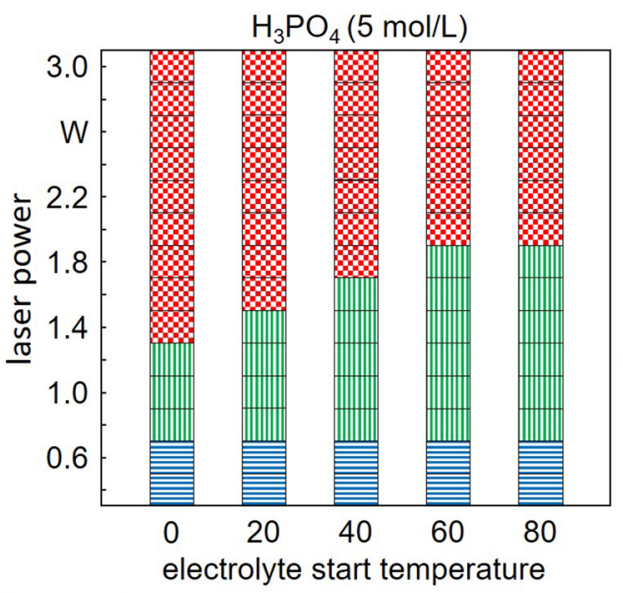

Simons 2020

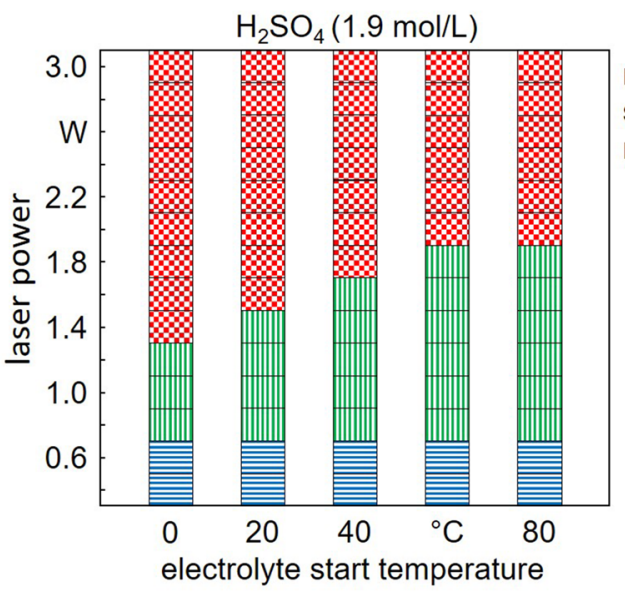

material Titanium Grade 1 spot diameter $\quad 25 \mu \mathrm{m}$ machining speed $\quad 50 \mu \mathrm{m} / \mathrm{s}$

$\begin{array}{rr}\underline{\underline{\underline{\underline{Z}}}} & \text { no removal } \\ \| \mathrm{II} & \text { undisturbed removal } \\ \mathcal{X} & \text { disturbed removal }\end{array}$

BIAS ID 200464

Fig. 4 Representation of the laser chemical process window at different electrolyte start temperatures

undisturbed removal regime to the disturbed removal regime is the same for both electrolytes.

Figure 5 represents an example of a material removal profile using phosphoric acid. At an electrolyte start temperature of $0{ }^{\circ} \mathrm{C}$, a disturbed, W-shaped removal profile results for all applied laser powers. At an electrolyte start temperature of $20^{\circ} \mathrm{C}$ and a laser power of $1.4 \mathrm{~W}$, an undisturbed removal profile can be seen, which is represented by the Gaussian-shaped removal. At laser powers of $1.6 \mathrm{~W}$ and $1.8 \mathrm{~W}$ a disturbed removal profile is visible. At the electrolyte start temperature of $40{ }^{\circ} \mathrm{C}$, undisturbed removal is visible at laser powers of $1.4 \mathrm{~W}$ and $1.6 \mathrm{~W}$. At $1.8 \mathrm{~W}$ there is a disturbed removal. If the electrolyte start temperature is increased to $60^{\circ} \mathrm{C}$ or $80^{\circ} \mathrm{C}$, the removals at the laser powers shown are Gaussian in shape and therefore undisturbed.

In addition, Fig. 6 shows the removal rates of phosphoric acid and sulfuric acid at different electrolyte start temperatures. As can be seen, the process window can be extended by increasing the electrolyte start temperatures to reduce the electrolyte viscosities. This extension allows the laser chemical process to be performed with higher laser powers. It follows that the maximum removal increases with increasing electrolyte start temperature. Compared to the maximum removal rate at an electrolyte start temperature of $20^{\circ} \mathrm{C}$, the removal rate at an electrolyte start temperature of $80^{\circ} \mathrm{C}$ was increased by a factor of 1.64 and 1.57 at phosphoric acid and sulfuric acid, respectively.

Furthermore, the removal rates are comparable at the same laser powers and different electrolyte start temperatures. Based in this, it can be seen from Fig. 6 that the electrolyte start temperature has a negligible influence on the removal rate in the present experiments.

\subsection{Evaluation of the Highspeed Videography}

Figure 7 shows the average bubble diameter during machining with different electrolyte start temperatures using phosphoric acid and sulfuric acid. The average bubble diameter

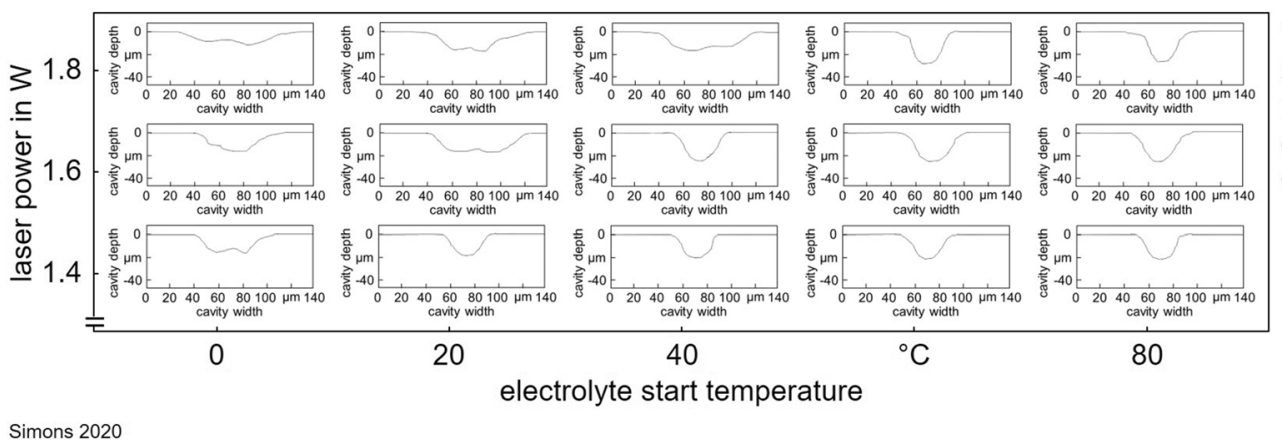

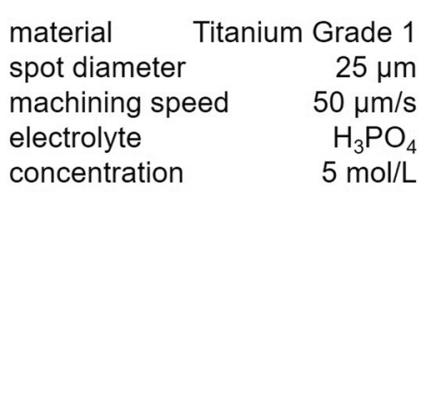

BIAS ID 200465

Fig. 5 Removal cavities at different electrolyte start temperatures 
Fig. 6 Removal rates at different electrolyte start temperatures
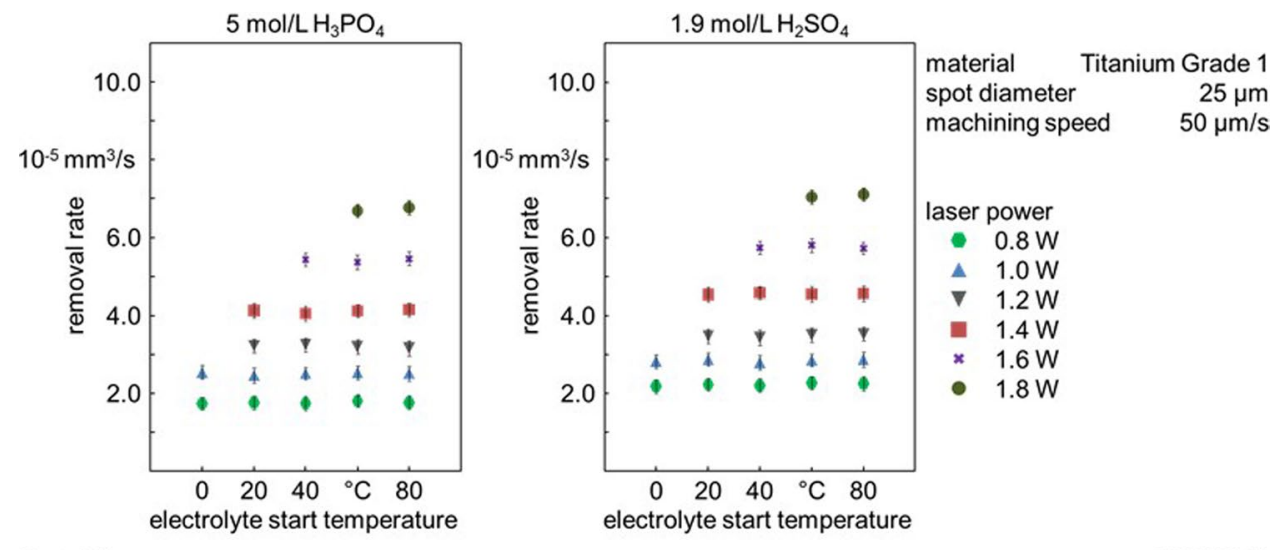

BIAS ID200466
Fig. 7 Representation of the averaged bubble diameters at different electrolyte start temperatures
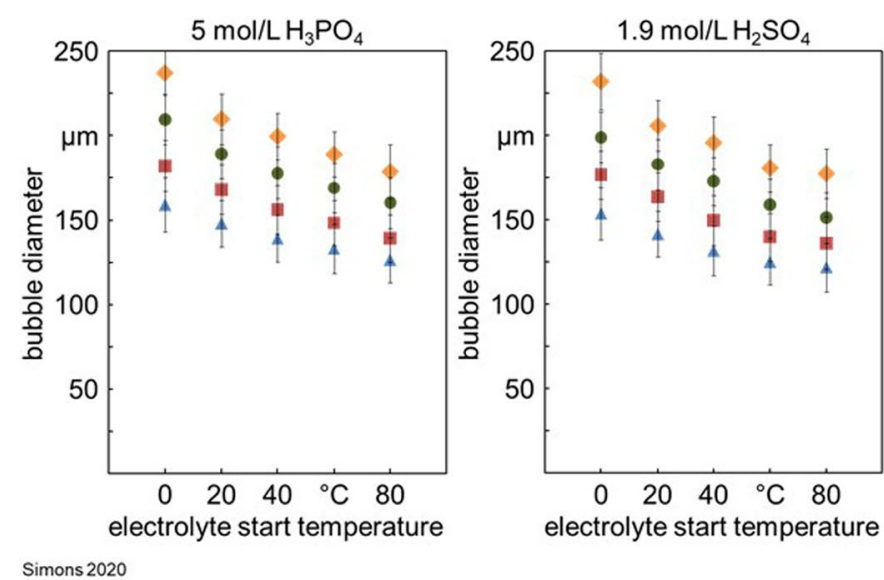

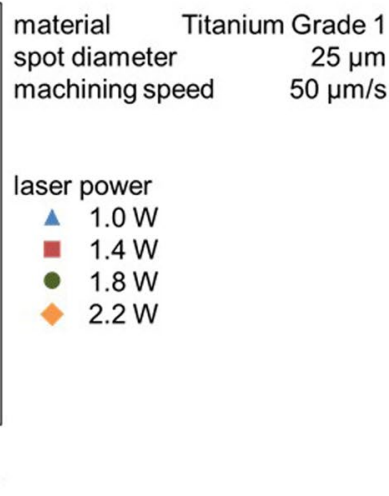

BIAS ID200467

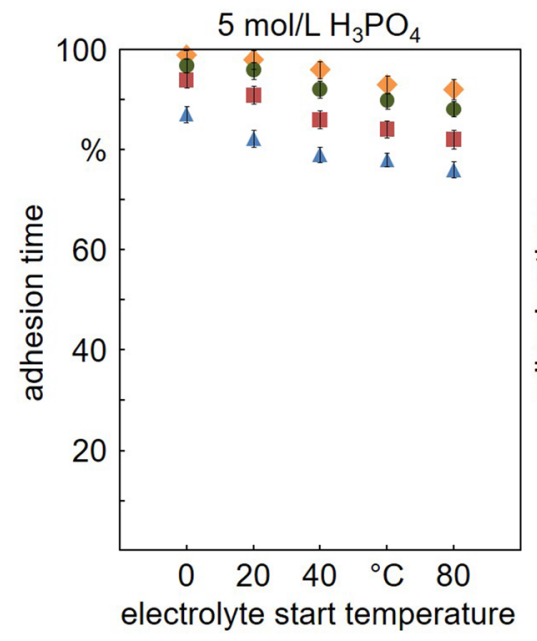

Simons 2020

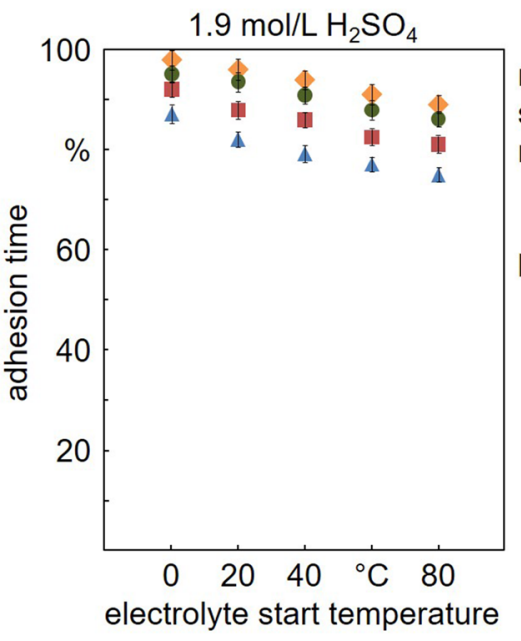

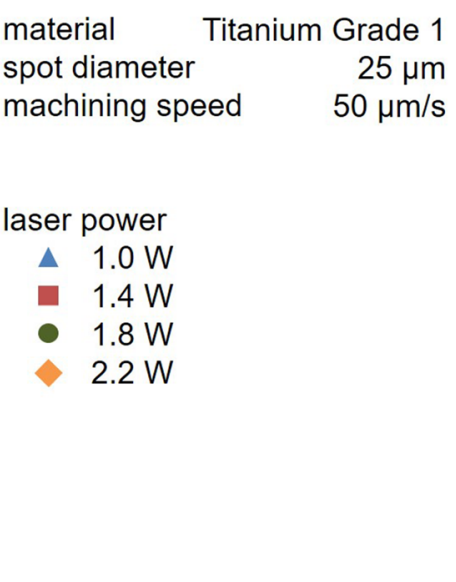

BIAS ID200468

Fig. 8 Representation of the adhesion times of the gas bubbles on the workpiece surface at different electrolyte start temperatures

decreases at higher electrolyte start temperatures, independent of the laser power used.
Figure 8 shows the percentage times at different electrolyte start temperatures at which the workpiece surface is covered with gas bubbles. As can be seen, at higher electrolyte 


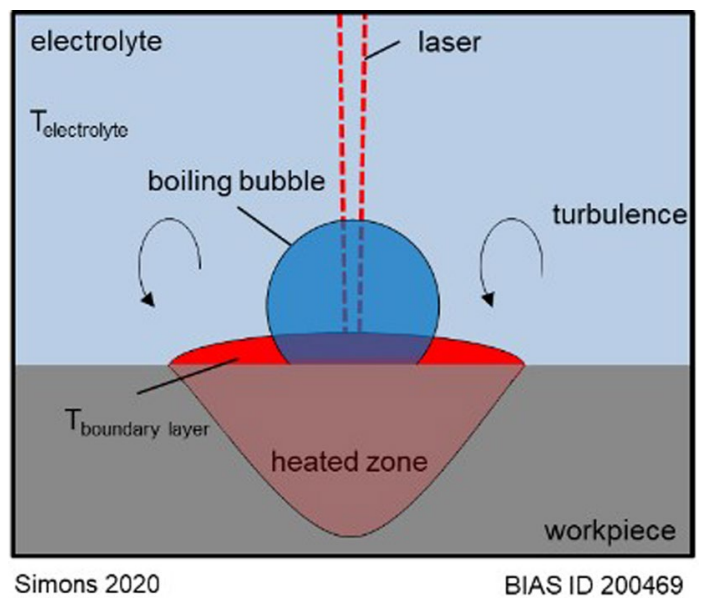

Fig. 9 Schematic representation of the laser chemical interaction zone

start temperatures the workpiece surface is free of gas bubbles over a longer period. At lower temperatures, the bubble adhesion time tends towards $100 \%$. From this point on, the workpiece is permanently covered by gas bubbles.

\section{Discussion}

In this study the influence of electrolyte start temperatures on the laser chemical process was investigated. As described in the introduction, both viscosity and surface tension decrease when the electrolyte start temperature is increased, see Fig. 2. A reduction of the viscosity accompanied with a reduction of the surface tensions shows in combination with the insights from [9] and [10] that the electrolyte boiling process is reduced. This can be seen from the reduction of the gas bubble diameters and the adhesion times of the gas bubbles to the workpiece surface, see Figs. 7 and 8. By reducing the electrolyte boiling process and the accompanied expansion of the process window, the laser chemical process can be carried out at increased laser powers. This allows higher removal rates, see Fig. 6.

As shown in Fig. 6, the different electrolyte start temperatures have no influence on the regime of non-existent removal. Even at an electrolyte start temperature of $80^{\circ} \mathrm{C}$, no measurable removal can be achieved at low laser powers. The results of the removal rate, see Fig. 6, show that the removal rates are not influenced by the electrolyte start temperature. This makes it clear that the influence of the electrolyte start temperature on the temperature field formed in the laser chemical interzone is negligible. During laser chemical machining, a thermal boundary layer is formed within the interaction zone (interface of laser radiation, electrolyte and workpiece surface) with a size of about $1 / 4-1 / 3$ of the boiling bubble size [15], see Fig. 9. The temperature of this boundary layer is largely determined by the laser-induced surface temperature [16]. Outside this boundary layer, the temperature of the electrolyte is significantly influenced by the set electrolyte start temperature.

It can therefore be assumed that the temperature at the site of the chemical dissolution reaction is largely determined by the set laser power. Based on these assumptions and the results from Figs. 4 and 6, it can be assumed that the electrolyte temperature has a negligible influence on the chemical dissolution reaction. However, the electrolyte start temperature has an effect on the electrolyte boiling process, which is reduced, see Figs. 7 and 8, and therefore enable the process window extension.

\section{Conclusions}

As the presented results show, an increase of the electrolyte start temperature reduce the gas bubble diameters and the adhesion time of the gas bubbles to the workpiece and thus the electrolyte boiling process. The dominant effect is the temperature-related reduction of the electrolyte viscosity. Reduced electrolyte boiling enables machining with higher laser powers and thus higher removal rates. The electrolyte start temperature has a negligible influence on the removal rates due to the thermal boundary layer that forms.

Funding Open Access funding enabled and organized by Projekt DEAL. This work has been funded by the Project 403820352- “Steigerung der Prozesseffizienz der laserchemischen Bearbeitung durch Vermeidung der gasblasenbedingten Abtragstörungen". The authors gratefully acknowledge the financial support by the Deutsche Forschungsgemeinschaft.

Open Access This article is licensed under a Creative Commons Attribution 4.0 International License, which permits use, sharing, adaptation, distribution and reproduction in any medium or format, as long as you give appropriate credit to the original author(s) and the source, provide a link to the Creative Commons licence, and indicate if changes were made. The images or other third party material in this article are included in the article's Creative Commons licence, unless indicated otherwise in a credit line to the material. If material is not included in the article's Creative Commons licence and your intended use is not permitted by statutory regulation or exceeds the permitted use, you will need to obtain permission directly from the copyright holder. To view a copy of this licence, visit http://creativecommons.org/licenses/by/4.0/.

\section{References}

1. Jahan, M. P., Rahman, M., \& Wong, M. S. (2011). A review in the conventional and micro-electrodischarge machining of tungsten carbide. International Journal of Machine Tools and Manufacture, 51(12), 837-858. 
2. Hsu, T. T. (2002). Miniaturisation-A paradigm shift in advanced manufacturing and education. In IEEE/ASME international conference on advanced manufacturing technology and education in the 21 st century.

3. Bäuerle, D. (2011). Laser processing and chemistry (2nd ed). Springer.

4. Stephen, A. (2011). Mechanisms and applications of laser chemical machining. Physics Procedia, 12, 261-267.

5. Stephen, A., \& Vollertsen, F. (2010). Mechanisms and processing limits in laser thermochemical machining. CIRP Annals, 59(1), 251-254.

6. Mehrafsun, S., \& Messaoudi, H. (2018). Dynamic process behavior in laser chemical micro machining of metals. Journal of Manufacturing and Materials, 2(3), 54-72.

7. Eckert, S., \& Vollertsen, F. (2020). Prozessbeschleunigung beim laserchemischen Polieren. Laser Magazin, 2, 20-23.

8. Simons, M., Radel, T., Shanta, V., \& Vollertsen, F. (2020). Comparison of boiling bubble behavior during laser chemical machining under superatmospheric pressure. In M. Schmidt, F. Vollertsen, \& E. Govekar (Eds.), Proceedings of the 11th CIRP conference on photonic technologies [LANE 2020] (Procedia CIRP 94) (pp. 561-564). Elsevier.

9. Zahedi, P., Saleh, R., Moreno-Atanasio, R., \& Yousefi, K. (2020). Influence of fluid properties on bubble formation, detachment, rising and collapse: Investigation using volume of fluid method. Korean Journal of Chemical Engineering, 31(8), 1349-1361.

10. Schnurmann, R. (1937). Über die Größe von Gasblasen in Flüssigkeiten (pp. 148-151). Phys. Chem. Lab.

11. DIN 53019-1. Viscometry-Measurement of viscosities and flow curves by means of rotational viscometers-Part 1: Principles and measuring geometry.

12. DIN EN 14370: Surface active agents-Determination of surface tension.

13. DIN ISO 50905-1:2009-09. Corrosion of metals-Corrosion testing-Part 1: General guidance.

14. Mehrafsun, S. (2018). Dynamisches Prozessverhalten bei der laserinduzierten thermochemischen Mikrostrukturierung von Metallen. Strahltechnik Bd. 67, eds. F. Vollertsen, R. Bergmann. BIAS Verlag Bremen.

15. Chen, H., Chen, G., Zou, X., Yao, Y., \& Gong, M. (2017). Experimental investigations on bubble departure diameter and frequency of methane saturated nucleate pool boiling at four different pressures. International Journal of Heat and Mass Transfer, 112, $662-675$.

16. Baehr, H. D., \& Stephan, K. (2010). Wärme- und Stoffübertragung (7th edn). Springer.

Publisher's Note Springer Nature remains neutral with regard to jurisdictional claims in published maps and institutional affiliations.

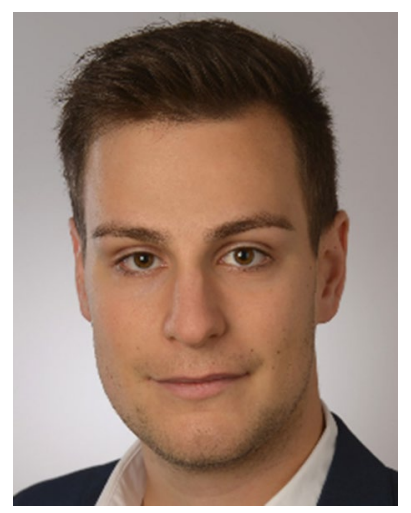

Marcel Simons Research associate at the Bremer Institute for Applied Beam Technology. His work focuses on micromachining processes, in particular laser chemical machining.

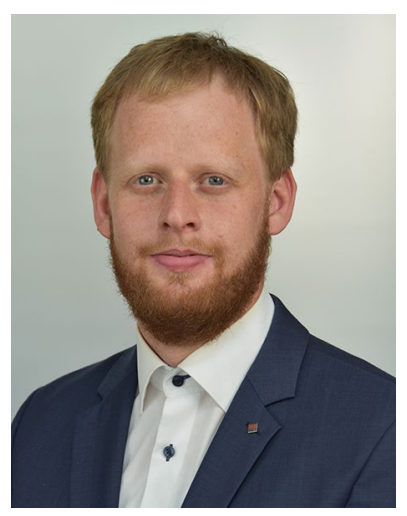

Tim Radel received his Dr. from the University of Bremen in 2020 and is currently head of department for Laser processing. His research interest are laser material processing with a focus on surface modifications of metallic surfaces by cw- and pwlasers, e.g. structuring, polishing and hardening.

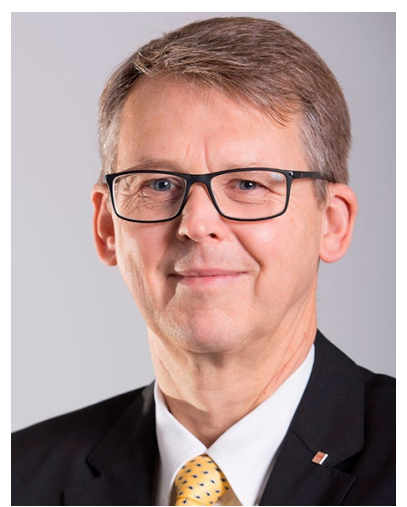

Frank Vollertsen Director of the BIAS - Bremen Institute for Applied Beam Technology and Professor in the Department of Production Engineering at the University of Bremen, Department of "Welding and allied Processes". 